\title{
Evaluation of the effectiveness of methods of compaction of sandy soil using physical modeling in the laboratory
}

\author{
Andrey Maltsev ${ }^{1, *}$, Alla Ponomarenko $^{1}$, Andrey Karpov ${ }^{1}$, and Dmitrii Popov ${ }^{1}$ \\ ${ }^{1}$ Samara State Technical University, Institute of Architecture and Civil Engineering, \\ 194, Molodogvardeyskaya St., 443001, Samara, Russia
}

\begin{abstract}
Surface compacting of soils is one of the measures applied in the practice of construction for the improvement of deformation and strength indicators of soil characteristics. Compacting is used both in creation of artificial bases in the shape of sand blankets and in quality enhancement of sand matresses for constructions as an underlying and levelling layer within road surface. For creation of surface compacting at a site various methods dependent on machines and mechanisms being used are applied: tamping, rolling, vibrocompaction. The research has been executed for evaluation of the efficiency of the indicated means of compacting. The set task was solved in laboratory conditions on physical models in a laboratory tray. In the course of the research the special laboratory tray was made, sandy soil model was chosen, with the help of additional equipment and developed original methodology a modelling of three methods of surface compacting was done, experiments on compacting of physical models with different soil dampness were executed, quantitative and qualitative assessments of surface compacting of sandy soil were given. On the bases of the conducted experiments the most efficient means of surface compacting of sandy soil was found. Recommendations for builders were given.
\end{abstract}

\section{Introduction}

Soil compacting is one of the measures executed at sites with the aim of preparation of structure bases. The main aim of soil compacting is to improve their mechanical characteristics. With the help of compacting deformity can be reduced and strength can be increased of both artificial bases (for instance, a sand blanket) and sand mattress or as an underlying and levelling layer within a road surface [1-3]. It is known that security of the system «construction-base» is determined by security of every element within this system [4]. That is why the condition of the road surface or appearance of additional deformations of construction bases will depend on the quality of the sand mattress and first of all on the level of its compacting $[5,6]$.

\footnotetext{
"Corresponding author: geologof@yandex.ru
} 
Analysis has shown that in the practice of construction various methods of surface compacting of sandy soil with the help of special machines and mechanisms are used: tamping, rolling, vibrocompaction (fig.1). Present research is conducted to answer the question which of the indicated means is more efficient?

The aim of this work is to value quality of various means of sandy soil compacting depending on its dampness.

The set task is solved in the laboratory conditions on physical models in the laboratory tray.

In the course of research the following actions were done:

- a laboratory tray for research conducting was issued;

- the necessary characteristics of the research object - sandy soil - were determined;

- in the laboratory tray with the help of additional equipment three means of surface compacting (tamping, rolling, vibrocompaction) were modeled;

- experiments on compacting of physical models with different soil dampness were conducted;

- quantitative and qualitative assessment of the considered means of surface compacting of sandy soil is given.

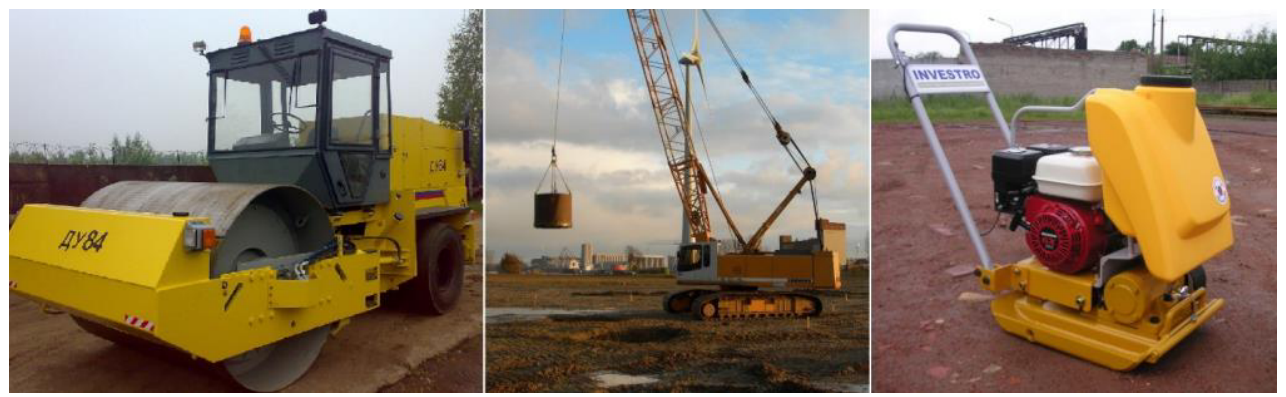

Fig. 1. Machines and mechanisms for surface compacting.

\section{Materials and methods}

The research was carried in several stages including preparation, experiment, processing and analysis of the experiment results.

At the stage of preparation to the physical experiment the laboratory flume especially for the research of surface compacting with different physical methods was designed and made (fig. 2,3). It represents a box with the dimensions of $24 \times 38 \times 50 \mathrm{~cm}$. Vertical walls of the laboratory tray are made of three sheetings of MDF and plexi. The bottom of the laboratory tray is made of a polymer sheeting set on the wooden battens.

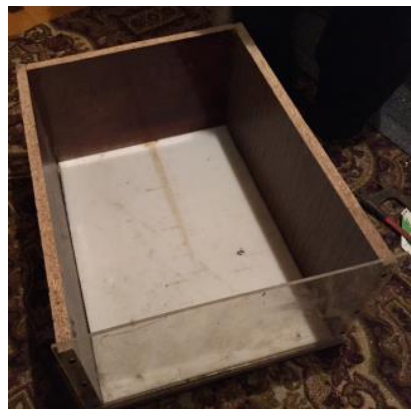

Fig. 2. Exterior of the laboratory tray.

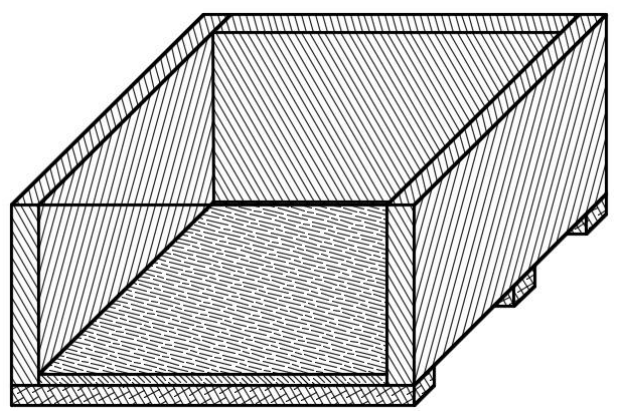

Fig. 3. Construction of the laboratory tray. 
Homogeneous sand of medium size was chosen as a research object. Analysis of its mechanical composition was made with the help of standard sieves (fig. 4) in accordance with the indications [7].

Before the beginning of experiments the potential of the soil under investigation for compacting was defined.

This was evaluated with the following physical parametres:

- full density dry sand equal to $\rho_{d \max }=1.74 \mathrm{~g} / \mathrm{cm}^{3}$;

- $\quad$ sand optimum moister content which made $W_{\text {opt }}=8.6 \%$.

Analysis of full density and optimum moister content was executed by the method of standard compacting in accordance with the requirements [8] with the help of special laboratory equipment (fig. 5).

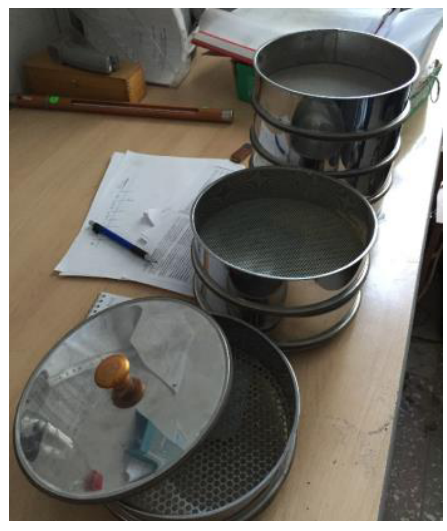

Fig. 4. A set of standard sieves.

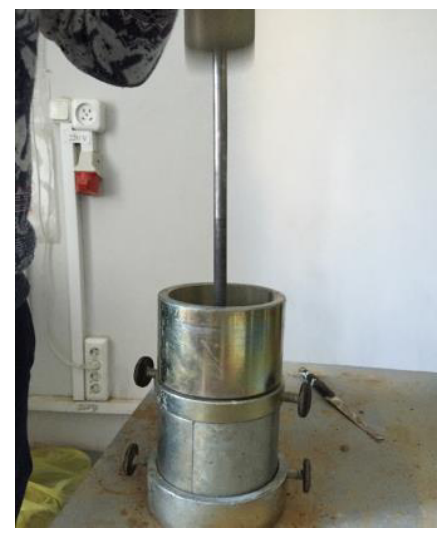

Fig. 5. Densometer.

An original methodology and special equipment permitting to model processes of surface soil compacting in the laboratory tray were developed to conduct the research conducting via the following means:

1. Tamping executed through the model of heavy compacting. In this case the level of sand (of $5 \mathrm{~cm}$ height) at the bottom of the laboratory tray was compacted by dynamic pressure done by a drop weight (total weight of $13 \mathrm{~kg}$ ) from the height of $20 \mathrm{~cm}$ along the guide bar on the timber slab of $25 \times 38$ dimensions (fig. 6) set on the soil surface. Production experiments determined technical parameters of the sample under investigation and compacting weight as well as minimal number of strikes with the aim of gaining maximum possible compacting for this means -5 strikes.

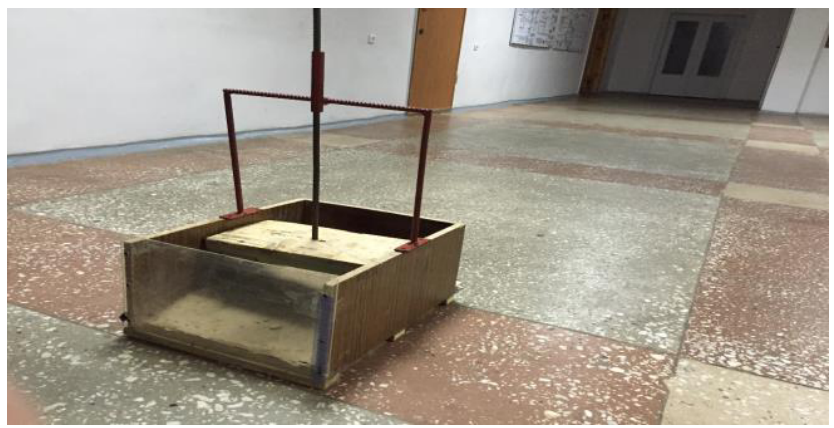

Fig. 6. Sand compacting in the laboratory tray by tamping.

2. Rolling. This type of compacting was executed by the model of a road roller - metal tubing with diameter of $70 \mathrm{~mm}$ and length of $50 \mathrm{~cm}$ filled inside with additional 
counterweight (total weight of $14 \mathrm{~kg}$ ). Sandy soil layer of $2.5 \mathrm{~cm}$ height was compacted under the influence of the tube weight which was relocated with the help of four preliminary rolled on it bundles of fishing line (fig. 7). Production experiments helped to define technical parameters of the sample under investigation and compacting weight as well as a minimal number of passages with the aim of gaining a full density for this means of compacting - 15 passes.

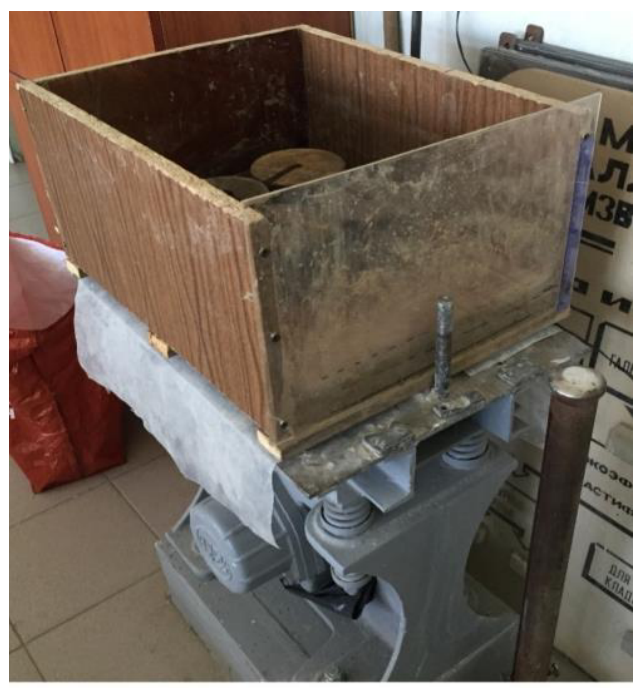

Fig. 7. Sand compacting in the laboratory tray by rolling.

3. Vibrocompaction. Was done in the laboratory tray with the help of a vibratory load created with the help of a special laboratory table vibrator (vibration frequency of $90 \mathrm{hz}$ ). The laboratory tray was filled with a sand layer of $2.5 \mathrm{~cm}$ height and was set on the table vibrator. Additional statictical weight was applied to soil surface in the shape of a beam $(25 \times 38 \mathrm{~cm}$ in dimension) and calibrated weight (fig. 8). Total weight was $27.7 \mathrm{~kg}$. Production experiments determined that vibrocompaction for 30 seconds is enough to reach possible full density of a sandy soil sample.

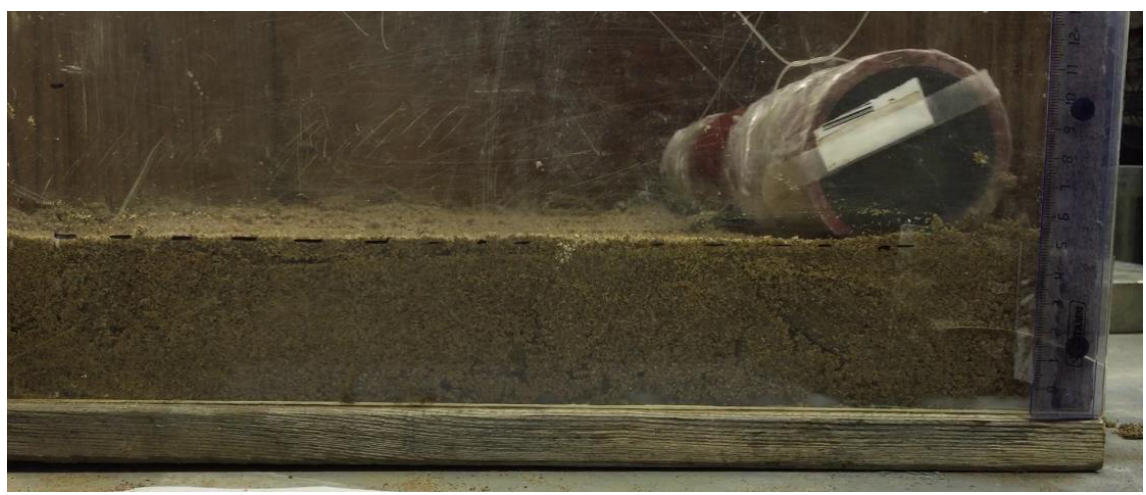

Fig. 8. Vibrocompaction of sand in the laboratory tray.

While conducting the experiments apart from the means of external influence on the soil the influence of moister content of the sandy soil sample on the amount of its density was investigated as well. In the experiments took part samples having the following moister content: $W_{l}=W_{\text {opt }}=8.6 \%, W_{2}=12.9 \%, W_{3}=17.2 \%, W_{4}=21.5 \%$. Thus for every means of 
compacting with various moister content of samples were conducted series of 12 experiments (total number of experiments was more than 40).

Control over the compacting of sandy soil samples in the course of experiments was done visually via a transparent wall of a laboratory tray and with the help of instruments via measurement of height of a sample with a ruler. After execution of the next experiment from the layer of a compacted soil not less than three samples were taken to determine their density $\rho_{i}$ by method of cutting ring in accordance with the instructions [9]. Mass specific gravity of the compacted sample $\rho_{a v}$ was calculated as an arithmetic mean of specials value of density of separate soil samples.

\section{Results}

For the evaluation of efficiency of the regarded means of compacting compaction factor $K_{c}$ which is applied in construction was chosen. This compaction factor is a relation of density of dry compacted sandy soil $\rho_{d}$ to its full density of dry soil $\rho_{d \max }$ determined at the stage of preparatory works.

Via experiments it was found out that the investigated sandy soil under optimum moister content $W_{\text {opt }}=8.6 \%$ had maximim compaction factor $K_{c}=0.92$. It should be marked that the given value is the least factor $K_{c}$ according to the Russian building regulations [10].

In the course of processing of experimental results on the basis of experimental data on the basis of recommended analytical decisions [7-10] for every experiment were determined:

- mass specific gravity of compacted soil sample $\rho_{\mathrm{av}}$;

- density of dry compacted sample of sandy soil $\rho_{d}$;

- compaction factor of a sandy soil sample $K_{c i}$.

The figures of the main indicators of density received as a result of the conducted experiments are given in table 1 .

Table 1. Cumulative results of tests on sandy soil compacting.

\begin{tabular}{|c|c|c|c|c|}
\hline \multirow{2}{*}{ Soil dampness } & \multirow{2}{*}{ Soil density } & \multicolumn{3}{|c|}{ Different means of soil compacting } \\
\cline { 2 - 5 } & & Tamping & Rolling & Vibrocompaction \\
\hline \multirow{3}{*}{$W_{I}=8.6 \%$} & $\rho_{a v}, \Gamma / \mathrm{cm}^{3}$ & 1.743 & 1.747 & 1.745 \\
\cline { 2 - 5 } & $\rho_{d}, \Gamma / \mathrm{cm}^{3}$ & 1.605 & 1.609 & 1.607 \\
\cline { 2 - 5 } & $K_{c}$ & 0.92 & 0.92 & 0.92 \\
\hline \multirow{3}{*}{$W_{2}=12.9 \%$} & $\rho_{a v}, \Gamma / \mathrm{cm}^{3}$ & 1.850 & 1.843 & 1.844 \\
\cline { 2 - 5 } & $\rho_{d}, \Gamma / \mathrm{cm}^{3}$ & 1.639 & 1.632 & 1.633 \\
\cline { 2 - 5 } & $K_{c}$ & 0.94 & 0.94 & 0.94 \\
\hline \multirow{3}{*}{$W_{3}=17.2 \%$} & $\rho_{a v}, \Gamma / \mathrm{cm}^{3}$ & 1.992 & 1.845 & 1.870 \\
\cline { 2 - 5 } & $\rho_{d}, \Gamma / \mathrm{cm}^{3}$ & 1.700 & 1.574 & 1.596 \\
\cline { 2 - 5 } & $K_{c}$ & 0.98 & 0.90 & - \\
\hline \multirow{3}{*}{$W_{4}=21.5 \%$} & $\rho_{a v}, \Gamma / \mathrm{cm}^{3}$ & 1.937 & 1.727 & - \\
\cline { 2 - 5 } & $\rho_{d}, \Gamma / \mathrm{cm}^{3}$ & 1.594 & 1.421 & - \\
\cline { 2 - 5 } & $K_{c}$ & 0.92 & 0.82 & - \\
\hline
\end{tabular}

\section{Discussion}

For quantitative and qualitative assessment of efficiency of the regarded means of surface compacting of sandy soil the received experimental data were represented as a graph (fig. 9) [11]. 


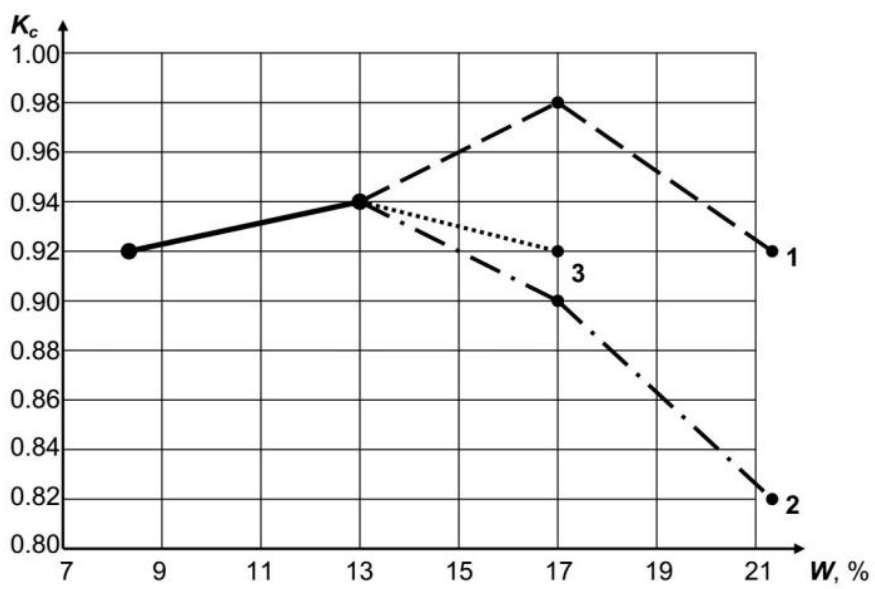

Fig. 9. Dependences between compaction factor and dampness with: 1 - tamping; 2 - rolling; 3 - vibrocompaction.

Comparison of special values of compaction factor $K_{c i}$ with maximum $K_{c}=0.92$ is given.

\section{Conclusions}

Conducted research of surface compacting of sandy soil with tamping, rolling and vibrocompaction showed the following:

1. When soil samples moister content is the limits from $9 \%$ to $13 \%$ all abovementioned means of sand compacting were characterised by approximately equal parametres.

2. All investigated means of compacting with sandy soil moister content from $13 \%$ to $15 \%$ showed compaction factor not less than the figure recommended by building regulations, i.e. of 0.92 [10].

3. When soil moister content was equal to $15 \%$ (in the middle of the varied segment of soil samples dampness) compaction factor by tamping is more than the corresponding figures for vibrocompaction on $3 \%$ and by rolling - on $4 \%$.

4. When sandy soil moister content increased on more than $15 \%$ the most effective means of surface compacting is tamping, the least effective is vibrocompaction, and rolling has the amount of compaction factor below the figure recommended by building regulations [10].

5. Vibrocompaction as a means of surface compacting of sands is effective with dampness up to $17 \%$. To execute vibrocompaction of sandy soil with big moister content indicators is difficult as in damp and water saturated sands a vibratory load is transferred not only to sand elements but to pore water. Density effect of particles decreases significantly.

5. The most effective according to the results of the conducted experiment was acknowledged the means of compacting by tamping with soil moister content of $17 \%$. In this case the experiment showed the biggest sand compaction factor -0.98 .

6. Despite the received experimental data while choosing the means of surface compacting of sandy soil on site it should be considered that tamping is connected with the application of a significant in size dynamic pressure to the soil body. This pressure may have a negative dynamic influence on the surrounding soil semi-environment and worsen the parameters of soils. That is why tamping is recommended for application on sites free 
from urban planning. In case of necessity in compacting of lower structures, foundations and soils of underground utility systems counterfill, construction and reconstruction of buildings in the constrained considtions on the territories with restrained urban conditions a means producing lower dynamic influence of the foundations of constructions placed nearby should be chosen. This may be a vibrocompaction, dynamic influence from which is more local and does not spread on considerable distances in a soil body.

\section{Acknowledgements}

The authors of the article are grateful to the bachelors of 4 year from the Department of engineering geology, bases and foundations, Faculty of Industrial and Civil Construction, Architecture and Civil Engineering Institute of Samara State Technical University - Sergey Fedorov and Eduard Karimov - for participation in the carrying out of this research.

\section{References}

1. L.G. Goverdovskaya, A.K. Yushantsev, Urban Construction and Architecture 1, 72-80 (2015) DOI 10.17673/Vestnik.2015.01.12.

2. A.V. Filatova, T.V. Dormidontova, E.S. Wilderotter, V.S. Seliverstov, Study of the processes and activities for major repairs of a road in the Samara region (LLC "Consulting company Ucom", Tambov-Samara, 2016) DOI: 10.17117/mon.2016.08.01

3. M.N. Baranova, N.G. Chumachenko, V.V. Turnikov, Urban Construction and Architecture 1, 80-85 (2014) DOI 10.17673/Vestnik.2014.01.14.

4. S.V. Evdokimov, T.V. Dormidontova, Urban Construction and Architecture 1, 64-68 (2012) DOI 10.17673/Vestnik.2012.01.12.

5. T.V. Dormidontova, A.V. Filatova, Procedia Engineering 153, 933-937 (2016) DOI: 10.1016/j.proeng.2016.08.256.

6. T. Dormidontova, S. Evdokimov, N. Shekhova, MATEC Web of Conferences 86, 04008 (2016) DOI: 10.1051/matecconf/20168604008

7. GOST 12536-2014. Soils. Laboratory determination of the grain (grain-size) and microaggregate composition (2014)

8. GOST 22733-2016. Soils. Laboratory method for determining maximum density (2016)

9. GOST 5180-2015. Soils. Methods of laboratory determination of physical characteristics (2015)

10. SP 45.13330.2012. Earthworks, bases and foundations. The updated edition of SNiP 3.02.01-87 (2012)

11. V.I. Isaev, A.V. Maltsev, A.A. Karpov, Procedia Engineering 153, 223-227, (2016) DOI: $10.1016 /$ j.proeng.2016.08.106 